\title{
Detection of biological uranium reduction using magnetic resonance
}

\section{Authors: Sarah J. Vogt, Brandy D. Stewart, Joseph D. Seymour, Brent M. Peyton, \& Sarah L. Codd}

NOTICE: This is the peer reviewed version of the following article: Vogt SJ, Stewart BD, Seymour JD, Peyton BM, Codd SL, "Detection of biological uranium reduction using magnetic resonance," Biotechnology and Bioengineering, April 2012 109(4):877-883, which has been published in final form at http://dx.doi.org/10.1002/bit.24369. This article may be used for non-commercial purposes in accordance with Wiley Terms and Conditions for Self-Archiving.

Vogt SJ, Stewart BD, Seymour JD, Peyton BM, Codd SL, "Detection of biological uranium reduction using magnetic resonance," Biotechnology and Bioengineering, April 2012 109(4):877-883 


\section{Detection of Biological Uranium Reduction Using Magnetic Resonance}

Sarah J. Vogt, ${ }^{1,2}$ Brandy D. Stewart, ${ }^{1,2}$ Joseph D. Seymour, ${ }^{1,2}$ Brent M. Peyton, 1,2 Sarah L. Codd 2,3

1 Department of Chemical and Biological Engineering, Montana State University, Bozeman, Montana

${ }^{2}$ Center for Biofilm Engineering, Montana State University, Bozeman, Montana;

3

Department of Mechanical and Industrial Engineering, Montana State University, 220 Roberts Hall, PO Box 173800, Bozeman, Montana 59717

The conversion of soluble uranyl ions $\left(\mathrm{UO}_{2}^{2} \mathrm{p}\right.$ ) by bacterial reduction to sparingly soluble uraninite $\left(\mathrm{UO}_{2}(\mathrm{~s})\right)$ is being studied as a way of immobilizing subsur-face uranium contamination. Under anaerobic conditions, several known types of bacteria including iron and sulfate reducing bacteria have been shown to reduce $\mathrm{U}$ (VI) to $\mathrm{U}(\mathrm{IV})$. Experiments using a suspension of uraninite $\left(\mathrm{UO}_{2}(\mathrm{~s})\right)$ particles produced by Shewanella putrefaciens $\mathrm{CN} 32$ bacteria show a dependence of both longitudinal (T1) and transverse (T2) magnetic resonance (MR) relaxation times on the oxidation state and solubility of the uranium. Gradient echo and spin echo MR images were compared to quantify the effect

caused by the magnetic field fluctuations $\left(\mathrm{T}^{*} 2\right)$ of the uraninite particles and soluble uranyl ions. Since the precipitate studied was suspended in liquid water, the effects of concentration and particle aggregation were explored. A suspension of uraninite particles was injected into a polysaccharide gel, which simulates the precipitation environ-ment of uraninite in the extracellular biofilm matrix. A reduction in the $\mathrm{T}_{2}$ of the gel surrounding the particles was observed. Tests done in situ using three bioreactors under different mixing conditions, continuously stirred, intermittently stirred, and not stirred, showed a quantifiable $\mathrm{T}_{2}$ magnetic relaxation effect over the extent of the reaction.

KEYWORDS: uranium; bioremediation; bioreduction; magnetic resonance; NMR; MRI

\section{Introduction}

The non-invasive detection of biogeochemical precipitation is an area of current research interest due to the role of precipitation of colloidal particles on subsurface transport processes (Dong et al., 2006; Fang et al., 2009; Novikov et al., 2006). In this work, the potential of magnetic resonance (MR) contrast to study the extent of reaction and spatial distribution of precipitate in the bacterial reduction of soluble uranyl ion $\left(\mathrm{UO}_{2}^{2} \mathrm{~b}\right)$ to insoluble uraninite $\left(\mathrm{UO}_{2}(\mathrm{~s})\right)$ is explored. The data indicate a strong magnetic susceptibility contrast due to the solid precipitate, which allows gradient recalled echo-imaging methods to determine spatial distributions of precipitate. Of importance for establishing in situ MR sensing methods to characterize biogeochemical precipitation reactions is the impact of particle size and sedimentation processes on MR contrast mechanisms. Monitoring U(VI) reducing bioreactors that were unmixed, mixed intermittently, and continuously stirred demonstrat-ed the ability of MR relaxation rates to characterize the precipitation reaction and particle sedimentation.

Several types of subsurface bacteria, e.g. Shewanella putrefaciens and Shewanella oneidensis, are being studied for use in bioremediation of uranium at nuclear waste sites (Abdelouas et al., 1998; Neal et al., 2004; Sani et al., 2008; Suzuki et al., 2002). The conversion from U(VI) to U(IV) produces uraninite $\mathrm{UO}_{2}$ (s) which is less soluble and precipitates to form nanoparticles. Spatially resolved MR techniques may be able to visualize uraninite particles as they precipitate around or in bacteria or within a biofilm. This will provide pertinent information on the nature of metal precipitation and subsequent immobilization in biofilms and allow for measurement of potential reoxidation within reduced-metal biofilms. Currently, there is not a 
technique to quantify or visualize this reductive immobilization process in a non-destructive manner. The ability to measure both the size and spatial distribution of the precipitate particles is important in modeling the transport of the contaminant. Whether bacterially produced uraninite particles undergo sorption processes to the microbes themselves, to the biofilm extracellular polymeric substance (EPS), or both can impact whether transport is enhanced or reduced. In the context of a conceptual model of transport (Flury and Qiu, 2008) for sorption of contaminants to organic colloidal particles, this research provides a technique to provide new data to develop analogous models for bioprecipitate colloidal contaminants and their role in transport.

MR studies of bioreactors have been undertaken for batch reactors of cell suspensions (As and Lens, 2001; Bartacek et al., 2009; Majors et al., 2008; Nott et al., 2001), packed beds (Seymour et al., 2004b, 2007; Tallarek et al., 1998; von der Schulenburg et al., 2008), and capillary reactors (Seymour et al., 2004a). Recent studies using MR have also been conducted considering the transport of colloids through porous media (Brosten et al., 2010; Creber et al., 2009). This work extends these studies to consider the impact of mobile nanoparticle precipitate reaction products. Direct MR of uranium has been measured (Ikushima et al., $2001)$, however due to the MR active isotope $(\operatorname{spin}=7 / 2)$ also being the radioactive isotope $\left({ }^{235} \mathrm{U}\right)$ with low natural abundance and low inherent signal, direct detection of uranium resonance is limited in its application.

\section{Materials and Methods}

\section{MR Relaxation}

MR relaxation experimental techniques have been used for years as a non-invasive and non-destructive tool to study, for example, the pore size distribution in rocks (Kleinberg et al., 1994) and as a contrast mechanism in medical MR imaging (Lauffer, 1987). The relaxation of MR signals occurs due to spin-lattice interaction in the longitudinal direction along the applied magnetic field $\left(T_{1}\right)$, and spin-spin dipolar interactions $\left(T_{2}\right)$. The $T_{2}$ relaxation is dependent on rotational mobility of the proton $\left({ }^{1} \mathrm{H}\right)$ spins, e.g. in a solid $T_{2}$ is short, on the order of $\mu$ s whilst in liquids it is long, on the order of seconds. Paramagnetic ions in solution provide dipole interactions that decrease $T_{2}$ (Abragam, 1961). Inhomogeneity in magnetic fields is caused by interfaces of materials with different magnetic susceptibilities, such as water and solid nanoparticle interfaces, generating additional spin-spin relaxation termed $T_{2}^{*}$. The relaxation caused by inhomogeneity in the magnetic field can be refocused if the time scale associated with the magnetization dephasing is long enough, but will contribute to the measured $T_{2}$ relaxation if the dephasing occurs over short time scales. Thus, differences between $T_{2}$ and $T_{2}^{*}$ effects is an indication of the presence of nanoparticles. $T_{1}$ relaxation is dependent on the applied magnetic field, translational mobility, and paramagnetic ions, but is less sensitive to these effects than $T_{2}$ at laboratory-strength magnetic fields.

\section{Washed $\mathrm{UO}_{2(\mathrm{~s})}$ Particle and $\mathrm{UO}_{2}^{2+}$ Solution Experiments}

To determine the impact of the uraninite nanoparticles on water proton relaxation in the absence of biomass or solution $\mathrm{UO}_{2}^{2+}$, a set of experiments was performed using a suspension of $\mathrm{UO}_{2(\mathrm{~s})}$ particles produced anaerobically by Shewanella putrefaciens $\mathrm{CN} 32$ in an anoxic chamber (Coy Laboratory Products Inc., Grass Lake, MI) containing a premixed gas of $90 \% \mathrm{~N}_{2}, 5 \% \mathrm{H}_{2}$, and $5 \% \mathrm{CO}_{2}$ (by volume), and then thoroughly washed to remove bacterial matter following the method described by Ulrich et al. (2008). The solution was centrifuged and then treated with $1 \mathrm{M} \mathrm{NaOH}$ to destroy intact cells, followed by incubation with anoxic hexane to separate any remaining organic matter. The reduced $\mathrm{U}$ was then resuspended in $100 \mathrm{mM}$ anoxic $\mathrm{KHCO}_{3}$ to remove any remaining $\mathrm{U}(\mathrm{VI})$ adsorbed on the $\mathrm{UO}_{2(\mathrm{~s})}$ particles. The suspension was then transferred into $5 \mathrm{~mm}$ MR tubes and sealed within the anoxic chamber. MR relaxation experiments were conducted to determine the relaxation dependence on the presence of $\mathrm{UO}_{2(\mathrm{~s})}$ particles. Lee et al. (2010) have shown using high-resolution transmission electron microscopy that while individual $\mathrm{UO}_{2(\mathrm{~s})}$ particles produced by Shewanella putrefaciens $\mathrm{CN} 32$ are about $3 \mathrm{~nm}$ in diameter, most nanocrystals occurred in aggregates $100 \mathrm{~nm}$ in diameter or larger. $T_{2}$ (CPMG) experiments (Carr and Purcell, 1954), spin echo images, gradient echo images (Callaghan, 1991), and $T_{1-}$ $T_{2}$ relaxation correlation experiments were used to quantify these effects. MR experiments were performed at $5.9 \mathrm{~T}$ $(250 \mathrm{MHz})$ using a DRX spectrometer (Bruker, Karlsruhe, Germany) and microimaging Micro5 probe with $2 \mathrm{~T} / \mathrm{m}$ magnetic field gradients in all three coordinate axes.

\section{$T_{2}$ Experiments}

The suspension of $\mathrm{UO}_{2(\mathrm{~s})}$ particles was shaken and $T_{2}$ experiments were performed every $12 \mathrm{~min}$ as the particles settled to observe the effect of particle concentration within the r.f. coil during the measurement. The CPMG experiments used 4,096 echoes at a spacing of $2 \tau=70 \mu \mathrm{s}$.

\section{Imaging Experiments}

Gradient echo and spin echo images were compared to observe the spatial distribution of the $T_{2}^{*}$ effect (Callaghan, 1991). The spin and gradient echo images had a slice thickness of $0.5 \mathrm{~mm}$, echo time ( $\left.T_{\mathrm{E}}\right)$ of $6.2 \mathrm{~ms}$, and repetition time $\left(T_{\mathrm{R}}\right)$ of $1 \mathrm{~s}$. Gradient echo images are attenuated by $T_{2}^{*}$ to which $T_{2}$ processes contribute, while spin echo techniques, as in the CPMG pulse sequence, partially refocus the inhomogeneous $T_{2}^{*}$ broadening of the signal and are primarily attenuated by $T_{2}$. Gradient and spin echo images were obtained using the same resolution, receiver 
gain, and echo time for direct comparison. The two images, gradient $(G)$ and spin echo $(S)$, were then repeated every $10 \mathrm{~min}$ over the course of an hour $(i=10-60 \mathrm{~min})$ as the nanoparticles were sedimenting through the active region of the r.f. coil. The signal from the same region of each image was integrated and the difference between the images in which particles had sedimented $\left(I_{(G, S), s}\right)$ and images with particles suspended $\left(I_{(G, S), i=10-60 \mathrm{~min}}\right)$ was calculated using:

$$
\Delta(G, S)_{i=10-60 \min }=\left(\frac{I_{(G, S), s}-I_{(G, S), i=10-60 \mathrm{~min}}}{I_{(G, S), s}}\right)
$$

The change in the spin echo-image intensity was then subtracted from the gradient echo change in intensity to quantify the increased attenuation in the gradient-recalled image $\left(\Delta G_{i=10-60 \mathrm{~min}}-\Delta S_{\mathrm{i}=10-60 \mathrm{~min}}\right)$, which reflects the inhomogeneous dephasing of the signal due to the magnetic susceptibility $T_{2}^{*}$ effect of the nanoparticles.

\section{Relaxation Correlation Experiments}

Two dimensional $T_{1}-T_{2}$ relaxation correlation experiments were also conducted as the uraninite particles were settling through the r.f. coil. These 2-D correlations have been shown to probe surface relaxation mechanisms in porous media and other applications (Callaghan et al., 2007; Song, 2009; Song et al., 2002; Washburn and Callaghan, 2006). $T_{1}-$ $\mathrm{T}_{2}$ experiments use an inversion recovery 180 degree pulse followed by a varying time to encode for the $T_{1}$ of the sample, followed by a CPMG pulse train to measure the $T_{2}$, as shown in Figure 1. An inverse Laplace transform is then performed, and the spectrum $F\left(T_{1}, T_{2}\right)$ is found by reducing the size of the data $M\left(t_{1}, t_{2}\right)$, then using a non-linear least squares algorithm and:

$$
\begin{gathered}
M\left(t_{1}, t_{2}\right)=\iint\left(1-2 \exp \left(\frac{-t_{1}}{T_{1}}\right)\right) \exp \\
\left(\frac{-t_{2}}{T_{2}}\right) F\left(T_{1}, T_{2}\right) d T_{1} T_{2}+E\left(t_{1}, t_{2}\right)
\end{gathered}
$$

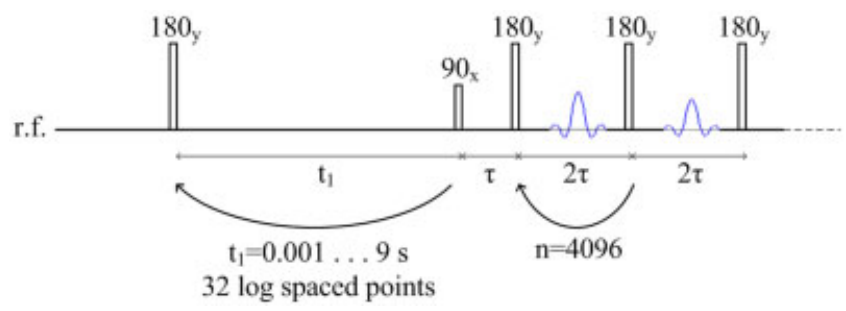

Figure 1. $T_{T}-T_{2}$ correlation pulse sequence. Experimental parameters: $T_{2}$ direction $-\tau=200 \mu \mathrm{s}, 2,048$ echoes; $T_{1}$ direction $-t_{1}$ varied from $1 \mathrm{~ms}$ to $9 \mathrm{~s}$ in 32 logarithmic steps. [Color figure can be seen in the online version of this article, available at http://wileyonlinelibrary.com/bit] where $E\left(t_{1}, t_{2}\right)$ represents the noise of the experiment (Washburn and Callaghan, 2006). Relaxation measurements were also performed on several different concentrations of the uranyl ion $\mathrm{UO}_{2}^{2+}$, and a linear dependence on both the $T_{1}$ and $T_{2}$ of the water protons was found (results not shown).

\section{Detection in Hydrogel Experiments}

The suspension of $\mathrm{UO}_{2(\mathrm{~s})}$ particles was injected into a xanthan gum/locust bean gum biomolecular hydrogel to simulate the precipitation of uraninite in the EPS of a biofilm. Spin and gradient echo images were again obtained with slice thickness $0.5 \mathrm{~mm}$, echo time $\left(T_{\mathrm{E}}\right)$ of $6.2 \mathrm{~ms}$, and repetition time $\left(T_{\mathrm{R}}\right)$ of $1 \mathrm{~s}$. Visual inspection indicated that the particles were in the wall region of the sample, as indicated by the image contrast in Figure 2. Note the strong refocusing of the susceptibility induced by the nanoparticles in the spin echo experiment relative to the gradient echo. This demonstrates the ability to use magnetic susceptibility contrast to determine the spatial distribution of biogeochemical reaction precipitates in biopolymer hydrogels similar to biofilm EPS. Previous studies have also shown the ability to use signal contrast due to heavy metal molecules to measure diffusion of the molecules into an alginate gel (Nestle and Kimmich, 1996).

\section{Bioreactor Experiments}

Finally, an experiment was conducted to validate the use of these concepts on an active bioreactor system. Two $10 \mathrm{~mm}$ NMR tubes were prepared with an initial concentration of $4 \mathrm{mM} \mathrm{UO}_{2}^{2+}$ as $\mathrm{UO}_{2} \mathrm{Cl}_{2}$, artificial groundwater medium

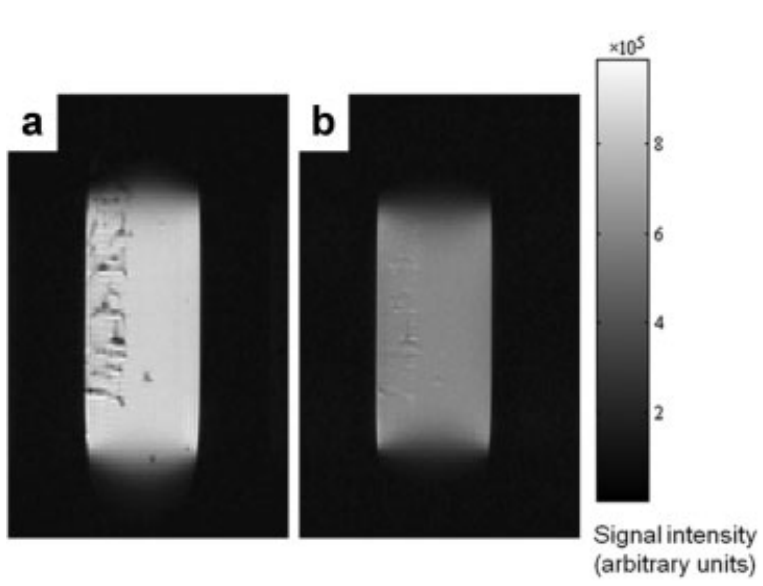

Figure 2. Uraninite particles $\left(\mathrm{UO}_{2(\mathrm{~s})}\right)$ injected into a xantham gum/locust bean gum gel. The enhanced signal attenuation around the injected particles in the gradient-recalled echo image (a) compared to the spin echo image (b) shows the $T_{2}^{*}$ effect on the gel surrounding the injected particles. Both images have the same intensity scale. Experimental parameters: $25 \mathrm{~mm} \times 10 \mathrm{~mm}$ FOV, $128 \times 128,0.5 \mathrm{~mm}$ slice thickness, $T_{\mathrm{E}}=6.2 \mathrm{~ms}, T_{\mathrm{R}}=1 \mathrm{~s}$. 
$\left(3 \mathrm{~g} / \mathrm{L} \mathrm{KHCO}_{3}, 1.5 \mathrm{~mL} / \mathrm{L}\right.$ mineral solution, $3 \mathrm{~g} / \mathrm{L}$ PIPES buffer, $0.005 \mathrm{~g} / \mathrm{L} \quad \mathrm{KCl}, 0.05 \mathrm{~g} / \mathrm{L}^{2} \mathrm{MgSO}_{4}, 0.03 \mathrm{~g} / \mathrm{L} \mathrm{NaCl}$, $1 \mathrm{~mL} / \mathrm{L} \quad \mathrm{NH}_{4} \mathrm{Cl}, \quad 1 \mathrm{~mL} / \mathrm{L} \quad \mathrm{KH}_{2} \mathrm{PO}_{4}, \quad 30 \mathrm{mM} \quad$ Na-lactate) and approximately $10^{8}$ cells $/ \mathrm{mL}$ Shewanella putrefaciens $\mathrm{CN} 32$ bacteria and sealed within the anoxic chamber. A $1 \mathrm{~L}$ stirred reactor was also prepared in the anoxic chamber and run concurrently with the tube reactors as a control experiment. Initially, it was not clear that the reaction would proceed within the sealed NMR tubes, which were not stirred constantly, so samples were taken from the larger stirred reactor every $24 \mathrm{~h}$ and tested with the two tube reactors to make sure that the reaction was proceeding as expected.

One of the two NMR tube reactors, referred to as "Reactor \#1", was frequently shaken to approximate the "stirred" reactor, and the other reactor, "Reactor \#2", was allowed to settle and was never shaken. This was done to determine if this reaction would also proceed in a static "biofilm" state as opposed to only occurring under stirred conditions. The reduction reaction from $\mathrm{UO}_{2}^{2+}$ to $\mathrm{UO}_{2(\mathrm{~s})}$ clearly still proceeded without shaking, as shown by the presence of dark particles in both Reactor \#1 and Reactor \#2 in Figure 3. A tube of the initial solution of media and $\mathrm{UO}_{2}^{2+}$ is shown in Figure 3 for comparison.

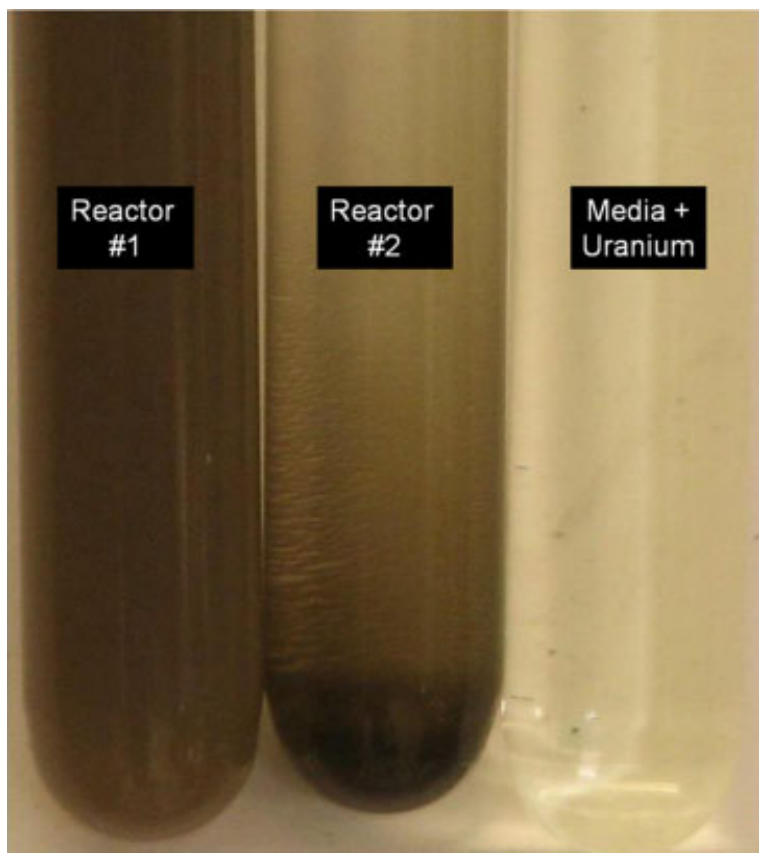

Figure 3. Two "reactors" that were compared during the bacterial reduction tests, with a tube of the starting media and $\mathrm{UO}_{2}^{2+}$ solution for comparison. Reactor \#1 was mixed intermittently during the experiment, while Reactor \#2 was not mixed. The dark particles in both Reactor \#1 and \#2 are the solid $\mathrm{UO}_{2}$ precipitate. These two reactors, as well as samples from a larger $1 \mathrm{~L}$ reactor, were tested in the bioreactor experiments. A tube of the initial solution of media and $\mathrm{UO}_{2}^{2+}$ is shown on the right for comparison. [Color figure can be seen in the online version of this article, available at http://wileyonlinelibrary.com/bit]

\section{Results and Discussion}

\section{Washed $\mathrm{UO}_{2(\mathrm{~s})}$ Particle and $\mathrm{UO}_{2}^{2+}$ Solution Experiments}

The linear dependence of both $T_{1}$ and $T_{2}$ relaxation on $\mathrm{UO}_{2}^{2+}$ ion concentration is consistent with treatment of the uranium as a paramagnetic species that enhances the relaxation of the surrounding solvent protons (Lauffer, 1987). This paramagnetism is due to the unpaired " $\mathrm{f}$ " and "d" electrons in the uranium atom (Blume, 1966). Water molecules around the $\mathrm{UO}_{2}^{2+}$ ions exchange between the coordination sphere around the ion and the bulk water, which causes increased magnetization relaxation (Swift and Connick, 1962).

\section{$T_{2}$ Experiments}

The transverse relaxation rate $R_{2}=1 / T_{2}$, as shown in Figure 4, was increased by the presence of $\mathrm{UO}_{2(\mathrm{~s})}$ nanoparticles. This is due to the strong magnetic susceptibility of the particles causing both homogeneous and inhomogeneous dephasing of the signal, resulting in a $T_{2}^{*}$ effect that is not refocused by the CPMG sequence due to susceptibility induced spin relaxation on a time scale less than the CPMG refocusing pulse spacing, i.e., $\tau_{\text {inhomogeneous }}<2 \tau_{\mathrm{CPMG}}=70 \mu \mathrm{s}$. As the larger particles settled out of the active region of the r.f. coil during the experiment, the relaxation rate continued to decrease approximately linearly.

\section{Imaging Experiments}

The maximum diameter of the particles settling through the active region was calculated by finding the maximum terminal settling velocity $v_{t}$ for each experiment using the length of the r.f. coil $(15 \mathrm{~mm})$ and the experiment time $\left(v_{t}=15 \mathrm{~mm} / i=10-60 \mathrm{~min}\right)$, and then using the force balance for a particle sedimenting in a viscous fluid

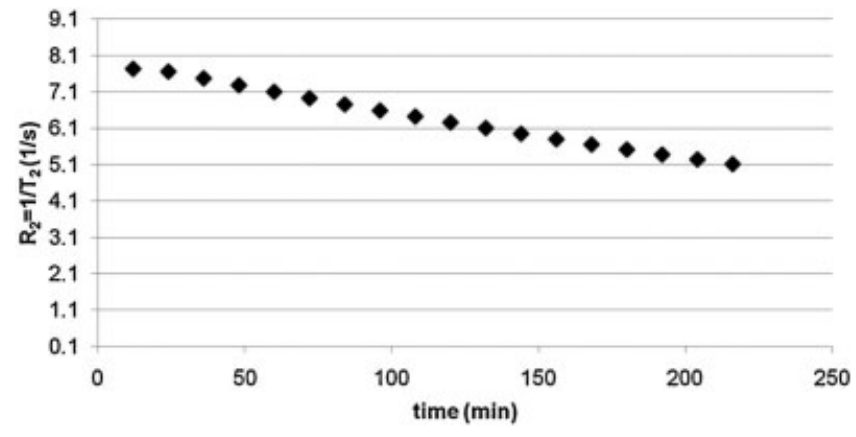

Figure 4. Relationship between relaxation rate $\left(R_{2}=1 / T_{2}\right)$ and the amount of time that the particles have been settling. The relaxation rate decreases with the decreasing presence of uranium nanoparticles. Experimental parameters: CPMG pulse sequence, $\tau=35 \mu$ s, 4,096 echoes. 


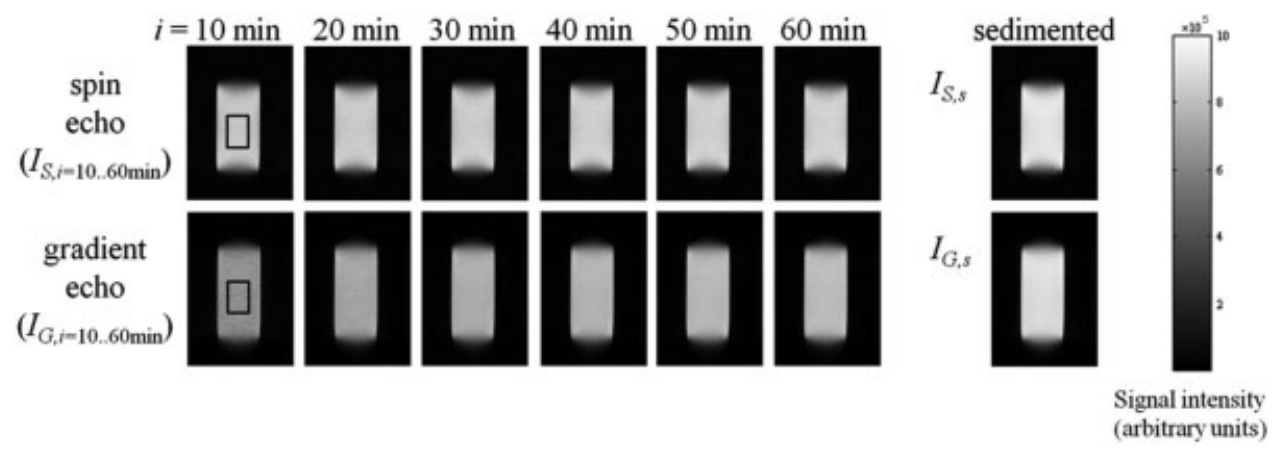

Figure 5. Images used to quantify $T_{2}^{*}$ effect of sedimenting particles. Spin echo (top row) and gradient echo (bottom row) images were taken after the particles had been settling overnight (far right) and were repeated for an hour after the sample had been stirred ( $i=10-60$ min). Images are shown using the same intensity scale. The region shown by the box in the images on the far left $(i=10 \mathrm{~min})$ was integrated to find the image intensity of each image. Experimental parameters: $25 \mathrm{~mm} \times 10 \mathrm{~mm}$ FOV, $128 \times 128,0.5 \mathrm{~mm}$ slice thickness, $T_{\mathrm{E}}=6.2 \mathrm{~ms}, T_{\mathrm{R}}=1 \mathrm{~s}$.

(Wilkes, 2006):

$$
D_{\mathrm{p}}=\sqrt{\frac{18 v_{t} \mu_{\mathrm{f}}}{g\left|\rho_{\mathrm{p}}-\rho_{\mathrm{f}}\right|}}
$$

where subscript " $\mathrm{p}$ " refers to the particle and " $\mathrm{f}$ " refers to the suspending fluid water. The dependence of the $T_{2}^{*}$ signal weighting $\quad\left(\Delta G_{i=10-60 \mathrm{~min}}-\Delta S_{i=10-60 \mathrm{~min}}\right) \quad$ calculated from the images of Figure 5 on the size of the particles is shown in Figure 6. The linear relationship shown between the $T_{2}^{*}$ relaxation and length scale is consistent with the well-known dependence of relaxation rate on surface to volume ratio of surface magnetization sinks (Brownstein and Tarr, 1979).

\section{Relaxation Correlation Experiments}

The $T_{1}-T_{2}$ correlation results in Figure 7 show that while the $T_{1}$ of the solution surrounding the settling particles stays essentially constant at approximately the $T_{1}$ of pure water, the $T_{2}$ varies by an order of magnitude between the unshaken sample and the shaken sample. While the peaks are about the same order of magnitude, the ratio $T_{1} / T_{2}$ varies from 12.8 for the freshly shaken sample to 1.5 for the "settled" sample. Even after allowing about 1 year for the particles to settle to the bottom of the sample tube, particles with a diameter of $9 \mathrm{~nm}$ or less were still suspended, and the effect of this is shown by the fact that $T_{1} / T_{2}$ ratio is still above the expected value of 1 for pure water. This demonstrates the quantification of the presence of $\mathrm{UO}_{2(\mathrm{~s})}$ by MR relaxation.

\section{Bioreactor Experiments}

The $T_{2}^{*}$ effect of the particles is shown in the gradient recalled echo images in Figure 8, indicating the increasing concentration of sedimented particles in the bottom of Reactor \#2, generating signal dephasing. The effects of the bacterial reduction of $\mathrm{U}(\mathrm{VI})$ to $\mathrm{U}(\mathrm{IV})$ on the $T_{1}$ and $T_{2}$ of the solution are shown in Figures 9 and 10. The $T_{1}$ result does not show a strong dependence on the presence of $\mathrm{UO}_{2(\mathrm{~s})}$ particles within the coil, consistent with the $T_{1}-T_{2}$ correlation results shown in Figure 8. However, the dependence on $T_{1}$ of the depletion of soluble $\mathrm{UO}_{2}^{2+}$ ions can be seen in the increase exhibited after 10,000 min for the two stirred reactors, Reactor \#1 and the $1 \mathrm{~L}$ constantly stirred reactor. The three reactors show a similar decrease of $T_{2}$ during the first 2 days of the reaction, and while the two stirred reactors continue to show the same trend the settled reactor diverges. This is due to the increase in particle

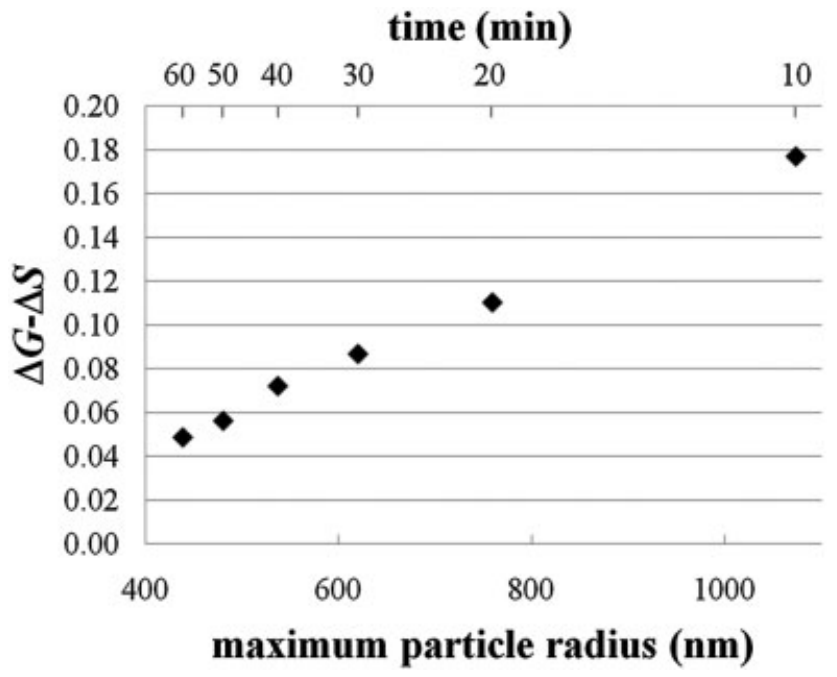

Figure 6. Demonstration of $T_{2}^{*}$ effect versus largest particles still suspended within the coil during the experiment, calculated using Equations (1) and (3) in the text and the images shown in Figure 5. 


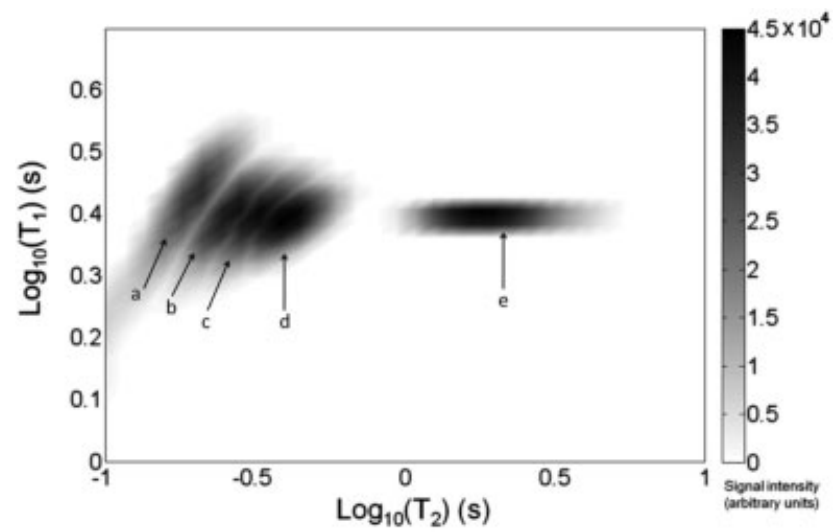

Figure 7. $T_{1}-T_{2}$ correlation spectra of solution surrounding settling washed uraninite $\left(\mathrm{UO}_{2(\mathrm{~s})}\right)$ particles at five different times, overlaid onto the same graph: (a) 0 $1.5 \mathrm{~h}$ after shaking the sample (b) 1.5-3h (c) 3-4.5 h (d) 4.5-6 h, and (e) 9,000 h (1 year) after shaking.

concentration due to reaction extent generating aggregation and sedimentation of the particles to the bottom of the reactor and causing them to cease affecting the $T_{2}$ of the solution. Because the stirred reactors always have particles of $\mathrm{UO}_{2(s)}$ within the coil during the experiment, the effect of the decreased concentration of the $\mathrm{UO}_{2}^{2+}$ dissolved in the solution is not visible. The error in the fit for the $T_{2}$ experiments is about $0.1 \%$, and the error for the $T_{1}$ experiments is $2 \%$.

\section{Conclusion}

The MR contrast of $\mathrm{UO}_{2(\mathrm{~s})}$ nanoparticles formed by biological reduction of $\mathrm{UO}_{2}^{2+}$ by Shewanella putrefaciens

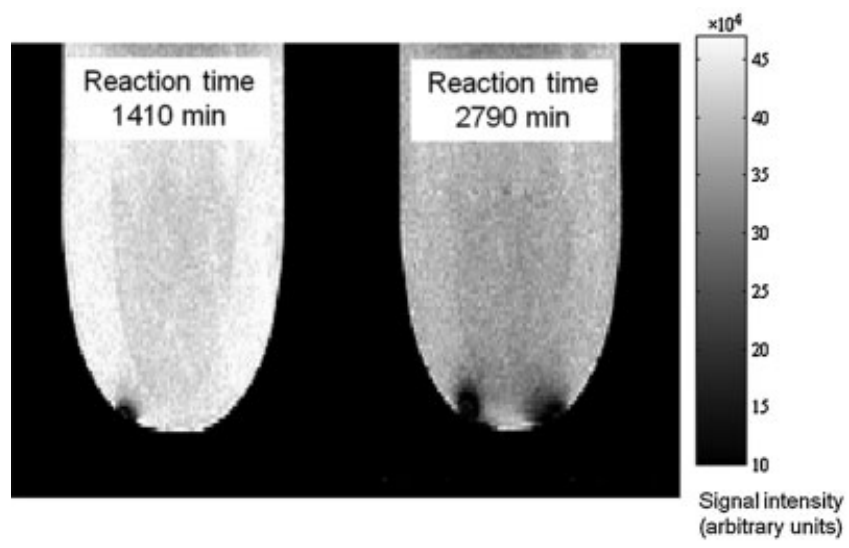

Figure 8. Gradient echo images of the bottom of Reactor \#2. The increasing concentration of uraninite $\left(\mathrm{UO}_{2(\mathrm{~s})}\right)$ particles settling into the bottom of the tube is shown by increased signal attenuation, both throughout the tube and particularly along the bottom surface. Both images have the same intensity scale. Experimental parameters: $25 \mathrm{~mm} \times 10 \mathrm{~mm}$ FOV, $128 \times 128,0.5 \mathrm{~mm}$ slice thickness, $T_{\mathrm{E}}=6.2 \mathrm{~ms}$, $T_{\mathrm{R}}=1 \mathrm{~s}$.

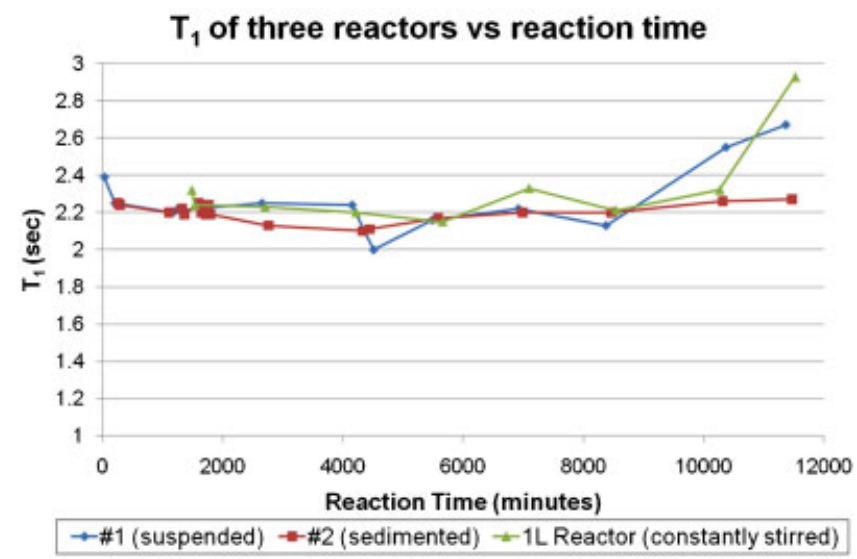

Figure 9. $T_{1}$ of the two $10 \mathrm{~mm}$ NMR tube bioreactors and samples from the $1 \mathrm{~L}$ continuously stirred bioreactor versus total bacterial reduction reaction time. $T_{1}$ was measured using an inversion recovery pulse sequence with 32 logarithmic spaced inversion times up to $5 \mathrm{~s}$. The $T_{1}$ for all three reactors throughout the extent of the reaction remains about constant. [Color figure can be seen in the online version of this article, available at http://wileyonlinelibrary.com/bit]

CN32 was shown to impact $T_{2}$ and $T_{2}^{*}$ MR relaxation. The MR techniques described provide a non-destructive means of measuring and understanding the complex process of microbially mediated $\mathrm{U}(\mathrm{VI})$ reduction to $\mathrm{UO}_{2(\mathrm{~s})}$, as well as the potential reoxidation and remobilization back to $\mathrm{U}$ (VI) and associated species. Using this method, spatial and temporal characterization of U-precipitate formation in geological systems would provide insight into the nanoparticle nature of reduction products and their distribution within complex, multi-phase systems. More traditional imaging techniques are often limited to providing information at the end of experiments and generally require

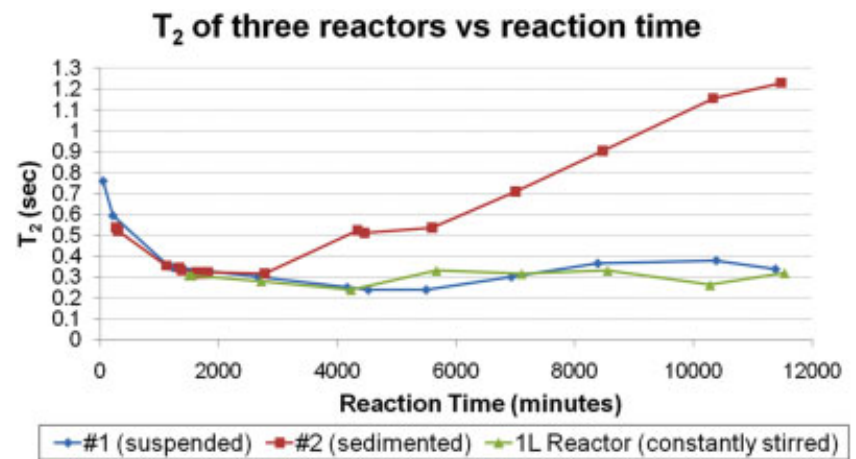

Figure 10. $T_{2}$ of the two- $10 \mathrm{~mm}$ NMR tube bioreactors and samples from the $1 \mathrm{~L}$ continuously stirred bioreactor versus total bacterial reduction reaction time. $T_{2}$ was measured using a CPMG pulse sequence with $\tau=35 \mu \mathrm{s}, 4,096$ echoes. The continued presence of $\mathrm{UO}_{2(\mathrm{~s})}$ particles within the coil for the two stirred reactors is shown by the divergence of the $T_{2}$ of the sedimented reactor (Reactor \#2) after about 3,000 min. [Color figure can be seen in the online version of this article, available at http:// wileyonlinelibrary.com/bit] 
termination and destruction of sample systems to obtain information. Data provided by non-invasive MR methods will provide valuable insights into the factors promoting uranium immobilization and has potential to improve the design of effective in situ remediation systems.

JDS, SLC, and SJV acknowledge funding from US DOE OS BER DEFG02-07-ER-64416 and DOE EPSCOR DE-FG02-08ER46527. The authors would like to thank Paul Callaghan for the inverse Laplace transform software. BDS and BMP acknowledge funding from Department of Energy's Subsurface Biological Research program under project number DE-FG02-07ER-64366.

\section{References}

Abdelouas A, Lu Y, Lutze W, Nuttall HE. 1998. Reduction of U(VI) to $\mathrm{U}(\mathrm{IV})$ by indigenous bacteria in contaminated ground water. J Contam Hydrol 35:217-233.

Abragam A. 1961. The principles of nuclear magnetism. Oxford: Clarendon Press.

As HV, Lens P. 2001. Use of ${ }^{1} \mathrm{H}$ NMR to study transport processes in porous biosystems. J Ind Microbiol Biotechnol 26(1-2):43-52.

Bartacek J, Vergeldt FJ, Gerkema E, Jenicek P, Lens PNL, Van As H. 2009. Magnetic resonance microscopy of iron transport in methanogenic granules. J Magn Reson 200(2):303-312.

Blume M. 1966. Theory of first-order magnetic phase change in $\mathrm{UO}_{2}$. Phys Rev 141(2):517-524.

Brosten TR, Fridjonsson EO, Codd SL, Seymour JD. 2010. NMR measurement of the transport dynamics of colloidal particles in an open cell polymer foam porous media. J Colloid Interface Sci 349(1):384-391.

Brownstein KR, Tarr CE. 1979. Importance of classical diffusion in NMR studies of water in biological cells. Phys Rev A 19(6):2446-2453.

Callaghan PT. 1991. Principles of nuclear magnetic resonance microscopy. Oxford: Clarendon Press.

Callaghan PT, Arns CH, Galvosas P, Hunter MW, Qiao Y, Washburn KE. 2007. Recent Fourier and Laplace perspectives for multidimensional NMR in porous media. Magn Reson Imaging 25(4):441-444.

Carr HY, Purcell EM. 1954. Effects of diffusion on free precession in nuclear magnetic resonance experiments. Phys Rev 94(3):630-638.

Creber SA, Pintelon TRR, Johns ML. 2009. Quantification of the velocity acceleration factor for colloidal transport in porous media using NMR. J Colloid Interface Sci 339(1):168-174.

Dong W, Xie G, Miller TR, Franklin MP, Oxenberg TP, Bouwer EJ, Ball WP, Halden RU. 2006. Sorption and bioreduction of hexavalent uranium at a military facility by the Chesapeake Bay. Environ Pollut 142:132142 .

Fang YL, Yabusaki SB, Morrison SJ, Amonette JP, Long PE. 2009. Multicomponent reactive transport modeling of uranium bioremediation field experiments. Geochim Cosmochim Acta 73(20):6029-6051.

Flury M, Qiu HX. 2008. Modeling colloid-facilitated contaminant transport in the vadose zone. Vadose Zone J 7(2):682-697.

Ikushima K, Tsutsui S, Haga Y, Yasuoka H, Walstedt RE, Masaki NM, Nakamura A, Nasu S, Onuki K. 2001. First-order phase transition in $\mathrm{UO}_{2}:{ }^{235} \mathrm{U}$ and ${ }^{17} \mathrm{O}$ NMR study. Phys Rev B 63(10):11.

Kleinberg RL, Kenyon WE, Mitra PP. 1994. Mechanism of NMR relaxation of fluids in rock. J Magn Reson A 108:206-214.
Lauffer RB. 1987. Paramagnetic metal-complexes as water proton relaxation agents for Nmr imaging-Theory and design. Chem Rev 87(5):901927.

Lee SY, Baik MH, Choi JW. 2010. Biogenic formation and growth of uraninite $\left(\mathrm{UO}_{2}\right)$. Environ Sci Technol 44(22):8409-8414.

Majors PD, McLean JS, Scholten JCM. 2008. NMR bioreactor development for live in-situ microbial functional analysis. J Magn Reson 192(1):159166.

Neal AL, Amonette JE, Peyton BM, Geesey GG. 2004. Uranium complexes formed at hematite surfaces colonized by sulfate-reducing bacteria. Environ Sci Technol 38(11):3019-3027.

Nestle N, Kimmich R. 1996. Heavy metal uptake of alginate gels studied by NMR microscopy. Colloids Surf A 115:141-147.

Nott KP, Paterson-Beedle M, Macaskie LE, Hall LD. 2001. Visualisation of metal deposition in biofilm reactors by three-dimensional magnetic resonance imaging (MRI). Biotechnol Lett 23(21):1749-1757.

Novikov AP, Kalmykov SN, Utsunomiya S, Ewing RC, Horreard F, Merkulov A, Clark SB, Tkachev VV, Myasoedov BF. 2006. Colloid transport of plutonium in the far-field of the Mayak Production Association, Russia. Science 314(5799):638-641.

Sani RK, Peyton BM, Dohnalkova A. 2008. Comparison of uranium(VI) removal by Shewanella oneidensis MR-1 in flow and batch reactors. Water Res 42:2993-3002.

Seymour JD, Codd SL, Gjersing EL, Stewart PS. 2004a. Magnetic resonance microscopy of biofilm structure and impact on transport in a capillary bioreactor. J Magn Reson 167(2):322-327.

Seymour JD, Gage JP, Codd SL, Gerlach R. 2004b. Anomalous fluid transport in porous media induced by biofilm growth. Phys Rev Lett 93(19):4.

Seymour JD, Gage JP, Codd SL, Gerlach R. 2007. Magnetic resonance microscopy of biofouling induced scale dependent transport in porous media. Adv Water Resour 30(6-7):1408-1420.

Song Y-Q. 2009. A 2D NMR method to characterize granular structure of dairy products. Prog Nucl Magn Reson Spectrosc 55(4):324-334.

Song Y-Q, Venkataramanan L, Hurlimann MD, Flaum M, Frulla P, Straley C. 2002. $\mathrm{T}_{1}-\mathrm{T}_{2}$ correlation spectra obtained using a fast two-dimensional Laplace inversion. J Magn Reson 154:261-268.

Suzuki Y, Kelly SD, Kemner KM, Banfield JF. 2002. Nanometre-size products of uranium bioreduction. Nature 419:134.

Swift TJ, Connick RE. 1962. NMR-relaxation mechanisms of ${ }^{17} \mathrm{O}$ in aqueous solutions of paramagnetic cations and lifetime of water molecules in first coordination sphere. J Chem Phys 37(2):307-320.

Tallarek U, van Dusschoten D, Van As H, Bayer E, Guiochon G. 1998. Study of transport phenomena in chromatographic columns by pulsed field gradient NMR. J Phys Chem B 102(18):3486-3497.

Ulrich KU, Singh A, Schofield EJ, Bargar JR, Veeramani H, Sharp JO, Bernier-Latmani R, Giammar DE. 2008. Dissolution of biogenic and synthetic $\mathrm{UO}_{2}$ under varied reducing conditions. Environ Sci Technol 42(15):5600-5606.

von der Schulenburg DAG, Holland DJ, Paterson-Beedle M, Macaskie LE, Gladden LF, Johns ML. 2008. Spatially resolved quantification of metal ion concentration in a biofilm-mediated ion exchanger. Biotechnol Bioeng 99(4):821-829.

Washburn KE, Callaghan PT. 2006. Tracking pore to pore exchange using relaxation exchange spectroscopy. Phys Rev Lett 97:175502-1175502-4.

Wilkes JO. 2006. Fluid mechanics for chemical engineers, 2nd edn. Upper Saddle River, NJ: Prentice Hall. 